\title{
Mental health in the midst of the covid-19 pandemic: a panoramic view of health professionals, affected patients and interpersonal relationships
}

DOI: $10.46932 / \mathrm{sfjdv} 2 \mathrm{n} 2-081$

Received in: March 1st, 2021

Accepted in: May 30th, 2021

\author{
Lauanna Freitas Pereira \\ Internal Doctor 9th period, by the Institution Universidade Nilton Lins \\ Address: Nilton Lins Street, 3259, Parque das Laranjeiras - Manaus, Amazonas, E-mail: \\ lauannafpereira2017@gmail.com
}

\section{Andresa Mota de Melo}

Internal Doctor 11th period, by the Institution Universidade do Estado do Amazonas Address: Carvalho

Leal Street, 1777, Cachoeirinha - Manaus, Amazonas,

E-mail: andresa.mota.melo@gmail.com

\section{Daniele da Silva de Souza}

Internal Doctor $11 \mathrm{~h}$ period, by the Institution Universidade Nilton Lins Address: Nilton Lins Street, 3259, Parque das Laranjeiras - Manaus, Amazonas,

E-mail: daniele.souza067@gmail.com

Dayene Bueno Cruvinel de Lima

Internal Doctor 10th period, by the Institution: Nilton Lins University

Address: Avenida Nilton Lins, 3259, Parque das Laranjeiras - Manaus, Amazonas

Email: dayenemed@ hotmail.com

\section{Emily dos Santos Silva}

Internal Doctor 11th period, by the Institution Universidade do Estado do Amazonas Address: Carvalho Leal Street, 1777, Cachoeirinha - Manaus, Amazonas

E-mail: emilydss@hotmail.com

\section{Gabriella Fonseca de Jesus Mesquita}

Internal Doctor 11th period, by the Institution Universidade do Estado do Amazonas

Address: Carvalho Leal Street, 1777, Cachoeirinha - Manaus, Amazonas

E-mail: fonsecagaab@gmail.com

\section{Gabrielle Rodrigues Tussolini}

Internal Doctor 10th period, by the Institution Universidade Nilton Lins Address: Nilton Lins Street, 3259, Parque das Laranjeiras - Manaus, Amazonas

E-mail: gabytussolini@hotmail.com

\section{Irlan Ariel Damasceno Silva}

Doctor, by the Institution Universidade do Estado do Amazonas

Address: Rua Japurá, 123, Cachoeirinha - Manaus, Amazonas

E-mail:irlan.ariel@gmail.com 


\begin{abstract}
The pandemic caused by the $S A R S-C o V-2$ virus provided a new global dynamic, reflecting on the lives of health professionals, people affected by the disease and interpersonal relationships. The main strategy adopted to curb contagion was social distance, with implications in several spheres: in family organization, in the closing of schools and public places and in work routines. This situation gave rise to feelings of helplessness, loneliness and disorders such as anxiety and depression, which directly or indirectly influence the morbidity and mortality of the disease. Health professionals are faced with a new routine, which requires countless hours of work in an exhaustive manner, concern with their patients and the unknown disease, in addition to the vulnerability of their family members. The general population is faced with difficulties in sustaining themselves, in treating chronic conditions and in the constant presence of fear and mourning. In this context, the need for investment and implementation of public policies aimed at mental health is concluded.
\end{abstract}

Keywords: Pandemic, SARS-CoV-2, Mental health.

\title{
1. INTRODUCTION
}

The World Health Organization (WHO), on March 11, 2020, characterized the new coronavirus disease (Coronavirus Disease-19 - COVID-19) as a pandemic, caused by the SARS-CoV-2 virus (Cucinotta\&Vanelli, 2020 ), which in the face of the lack of specific treatment that proved to be effective and vaccines led the population to face as the main strategy to curb the number of contagions, social distance, a measure that did not apply to health professionals on the front line who face this daily challenge (Teixeira et al., 2020). 


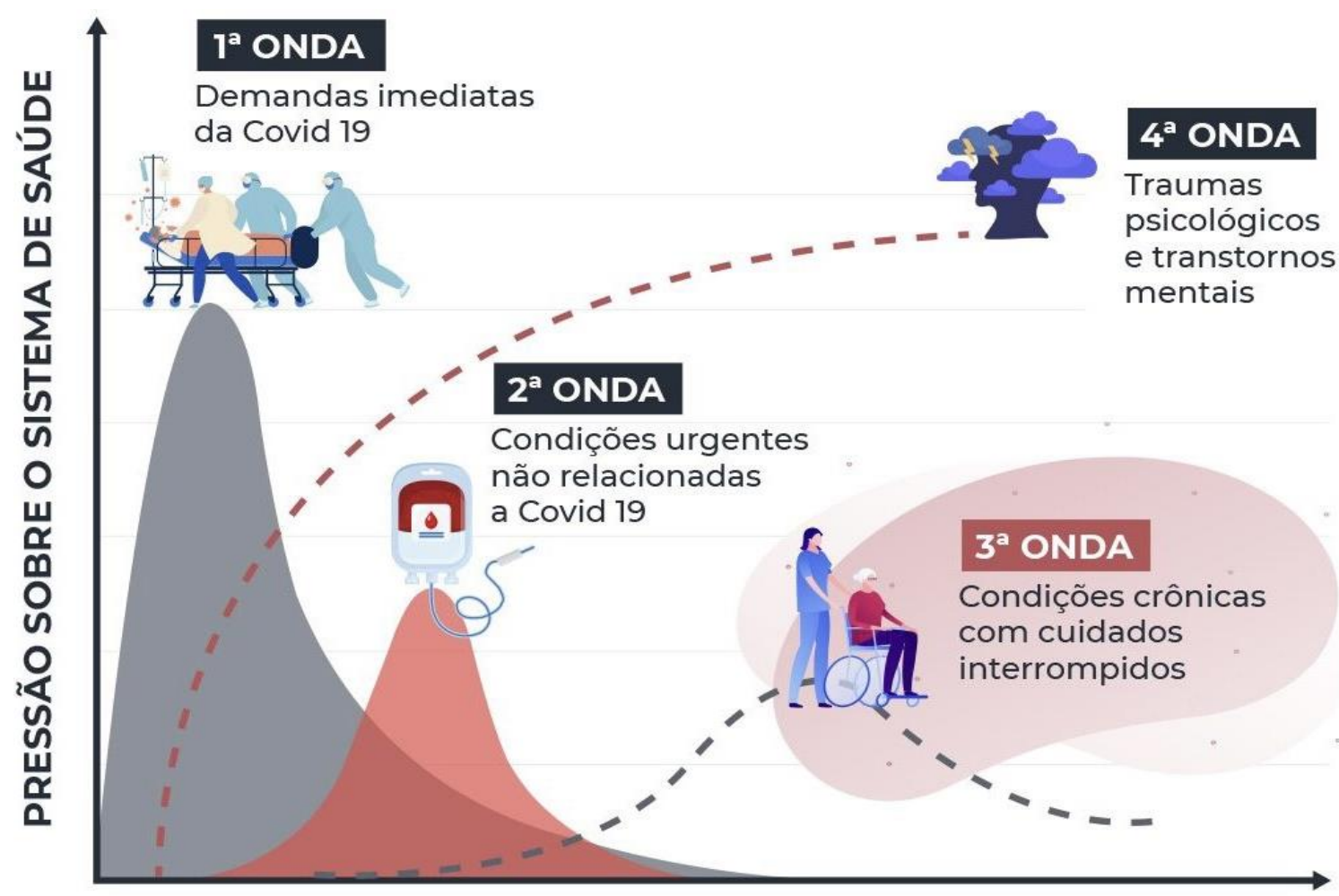

IMAGE 1: The first wave, formed by the immediate clinical demands of patients with Covid-19: hospitalization, ventilation and death, concentrated mainly in high-risk groups. The second brings patients with urgent conditions unrelated to Covid-19 in parallel. The third is driven by those with chronic conditions whose care has been interrupted. And the fourth wave will include psychological traumas and disorders and mental illnesses, especially in those who suffered the most from confinement or the loss of loved ones who could not even say goodbye - or who, militating in groups at risk, continue to suffer in the face of from the perspective of becoming infected.

Indiligence with mental health was even more evident, with the increase in psychosocial demand caused by the effects of the pandemic. According to the WHO, in 2020, about 1 billion people faced some form of mental disorder. Disproportionately, a small portion of those affected has access to some type of mental health care, a fact that favors the increase in the number of tragic outcomes such as suicide (World Health Organization, 2020).

Levels of loneliness, worries, anxiety and precautionary behaviors in response to the pandemic were some of the feelings observed by Varga et al., (2021) in the European population. The risk of falling ill or of someone close to you was reported as one of the biggest concerns of the interviewees.

The pandemic has also had major effects on the mental health of those on the front lines. Working in stressful conditions, with a high workload, fear of infecting their families and loved ones, lack of clarity about the effective treatment of patients affected by COVID-19, ended up providing a traumatic experience to these professionals who report more and more the occurrence of symptoms of anxiety, depression, loss of sleep quality (Kola et al., 2021; Teixeira et al., 2020). 
According to Barroso et al. (2020), in relation to tackling the pandemic of COVID-19, Brazilian states have promoted individual and collective actions to deal with health and economic impacts.

Referring specifically to healthcare workers, Barroso et al. (2020) also mention the main challenges they experienced in coping with the epidemic, among them are: the high degree of contagion of the virus, the lack of personal protective equipment (PPE), work overload and health mental impacts.

A new question arises among health professionals as stated (McConnell, 2020) - the question of the balance between the duty to treat and the duty to the family in the context of the COVID-19 pandemic. In this there are several complicating factors, which include the role of the health professional, the vulnerability of family members to illness and the resources available for the health professional to protect their family.

The health system in several countries is overburdened by the pandemic and this has compromised the standard of care to be provided. This scenario is not only due to the lack of physical resources such as life support equipment, but it is also related to the insufficient number of health workers.

According to McConnell (2020), a survey found that concern for family safety was the most frequently cited factor in reducing the willingness to work during a pandemic. Thus, it is not surprising that there have been cases of health professionals refusing to work in the face of this scenario. There are reports of social workers in a nursing home in Australia who refused to work after an outbreak of COVID19 at their facility, citing this concern.

According to Ornell, Schuch, et al. (2020), during pandemics, it is common for health professionals, scientists and managers to focus predominantly on the pathogen and biological risk, in an effort to understand the pathophysiological mechanisms involved and propose measures to prevent, contain and treat the disease. In these situations, the psychological and psychiatric implications secondary to the phenomenon, both at the individual and the collective level, tend to be underestimated and neglected, creating gaps in coping strategies and increasing the burden of associated diseases.

Honorato et al. (2020) exposes the situation of health professionals as a critical point, as many are emotionally exhausted and have Burnout syndrome; suffering from separation from the family, fear of dying, fear of becoming infected, loss of colleagues, insomnia.

\section{EXPERIENCE OF PATIENTS AFFECTED BY COVID-19}

Ornell et al. (2020) explained that during epidemics, the number of people whose mental health is affected tends to be greater than the number of people affected by the infection. Previous tragedies have shown that the implications for mental health can last longer and have a higher prevalence than the epidemic itself and that the psychosocial and economic impacts can be incalculable if we consider its 
resonance in different contexts. As the economic costs associated with mental disorders are high, improving mental health treatment strategies can lead to gains in both physical health and the economic sector.

In addition, the pandemic causes a concrete fear of death and has implications for other spheres: family organization, closing schools, companies and public places, changes in work routines, isolation. Such changes develop feelings of helplessness and abandonment and may even increase insecurity, due to the large-scale economic and social repercussions.

Also according to Ornell, Schuch, et al. (2020), a Chinese study provided some ideas in this regard. Approximately half of the respondents rated the psychological impact of the epidemic as moderate to severe and about a third reported moderate to severe anxiety. Similar data have been reported in Japan, where the economic impact has also been dramatic. Another study reported that patients with a suspected and / or confirmed case may experience intense emotional and behavioral reactions, such as fear, boredom, loneliness, anxiety, insomnia or anger.

According to Xiang et al. (2020) specifically for this new COVID-19 scenary, there are major factors that must be considered when developing mental health strategies:

1) multidis iplinary mental health teams (including psychiatrists, psychiatric nurses, clinical psychologists and other mental health professionals)

2) clear communication involving regular and accurate updates on the COVID-19 outbreak

3) establishment of safe psychological counseling services (for example, via electronic devices or applications)

4) regular clinical screening of depression, anxiety and suicide by mental health professionals for suspected patients diagnosed with pneumonia 2019-nCoV, as well as health professionals working in hospitals that care for infected patients.

It is extremely necessary to implement public mental health policies in conjunction with strategies to respond to epidemics and pandemics before, during and after the event.

Health professionals such as psychologists, psychiatrists and social workers, must be at the forefront and play a leading role in emergency planning and management teams.

Assistance protocols, such as those used in disaster situations, must cover areas relevant to the individual and the collective mental health of the population. Recently, WHO and the US Center for Disease Control and Prevention published a series of psychosocial and mental health recommendations.

This is in line with WHO longitudinal data, which shows that psychological factors are directly related to the main causes of morbidity and mortality worldwide. Thus, there is a need for increased 
investment in research and strategic actions for mental health in parallel with infectious outbreaks worldwide.

According to the narrative review by Chevance et al. (2020), carried out in France, four types of main vulnerabilities were identified among patients with mental disorders during this pandemic:

1) medical comorbidities most frequently found among patients with mental disorders (cardiovascular and pulmonary pathologies, diabetes, obesity etc.) risk factors for severe covid-19 infection

2) age (the elderly make up the population most vulnerable to coronavirus)

3) cognitive and behavioral disorders, which can make it difficult to comply with containment and hygiene measures and, finally.

4) psychosocial vulnerability as a result of stigmatization and / or socioeconomic difficulties.

In addition, the mental health system is more vulnerable than other health systems.

Current government plans are poorly suited for psychiatric establishments in a context of great scarcity of organizational, material and human resources.

Two letters to the editor can be highlighted, one by Yao et al. (2020) and another by Zhu et al. (2020) about inpatients in psychiatry in China. Chinese colleagues warn of the vulnerability of psychiatric patients and deplore the lack of interest in authorities and the scientific community.

In this pandemic scenariy, patients with psychological disorders have three specific areas of vulnerability in relation to the epidemic: vulnerability associated with comorbidities.

Outside the epidemic context, patients hospitalized in psychiatry with schizophrenia, bipolar disorders, depression, anxiety disorders or autism with a higher risk of pneumococcal infection. More broadly, due to immunological fragility, these patients have greater difficulty in fighting infections, as shown by epidemiological studies on numerous cases of infections such as toxoplasmosis and herpes during the course of psychiatric pathologies. In addition, they are much more affected by comorbidities than the general population, which are serious risk factors for SARS-Cov-2 infections.

According to Honorato et al. (2020), the pandemic moves in waves around the planet, spreading geographically and it is possible to verify not only the progress from the topographical point of view, but also how it affects emotional health. It started in China and in some Asian countries, such as Thailand, Japan and South Korea, until reaching the United States and France, still in January 2020.

The first major impact, after China, was in Italy, which had its first case on January 30, 2020 and the first death is already in February.

Italy has induced most countries to adopt more drastic measures, such as total isolation (bloc) and border closure. 
Still according to Honorato et al. (2020), the first wave happens as soon as the population is informed by the local news that the virus has already reached the cities.

Then the first symptoms appear in patients and researchers: increased levels of anxiety; depression; fear of contagion, fear of unemployment; social risks and consequences, fear of death; loneliness / social isolation; increases in alcohol and drug consumption, insomnia, easy irritation; fear of returning to work, lack or excess of information; fear of scarcity of resources (treatment, medication), maternity / pregnancy during a pandemic.

The second wave occurs in the course of the pandemic and when a death occurs, the symptoms of the first wave are accentuated. Some new complaints are: financial difficulty; domestic violence; emotional isolation; stigma; difficulty in dealing with home schooling.

The reality of patients affected by Covid-19 is well portrayed by Honorato et al., (2020):

Covid-19 home-care people begin to seek help to deal with the fear of death and isolation, separated from their loved ones, in the same house. Those admitted to hospitals in milder conditions also seek emotional refuge in networks and forms of online care.

Parents have domestic difficulties due to anxiety or irritability.

As the pandemic progresses and the number of deaths increases, the number of people seeking psychological help to deal with the pain increases. The dead are no longer numbers and statistics, they have a first and last name and affective bond. There are no longer a certain number of deaths per day, but a brother, a cousin or even a husband, father or mother. Professionals then begin to deal with the elaboration of mourning, considering that the ritual of watching over the body and burial is restricted by health rules, modified in many countries.

The same author mentioned above highlights as a note that between the first and the second wave, the number of suicides and suicidal ideation increased among the general population, either because of the fear of the unknown in the first phase, or because of the suffering faced in the second.

Through Honorato et al. (2020), we are led to think about what we can extract from previous experiences, related to wars and another period of pandemic: there will be an increase in the number of cases of anxiety disorder, especially post-traumatic stress disorder (PTSD).

Among children and adolescents, in pediatric care in the city of Manaus, Amazonas, we see an exponential increase in cases of depression, self-extermination, binge eating, metabolic syndrome and childhood obesity on a daily basis.

The pandemic experience leads people to turn to fatality, which weakens individual promises for the future and strengthens shared care attitudes. Despite the suffering resulting from this current 
scenario, it can be predicted that there will be a favoring or recognition of inequalities and promotion of citizenship and rights.

\section{MENTAL HEALTH OF THE GENERAL POPULATION DURING THE VALIDITY OF THE PANDEMIC}

According to Brooks et al. (2020) in view of the psychological repercussions that social distancing can promote, some measures can be taken to make it as less harmful as possible. The minimum time indicated for quarantine has been two weeks, which is the incubation period for the COVID-19 virus. Even though this period is extended, it is important that it lasts, as long as necessary, as little as possible to be less harmful to mental health.

Pancani et al. (2020) reports that another strategy for making quarantine less harmful is information. People should be informed of what is happening and the reasons, explaining how long it can last, keeping them informed about the importance of staying at home.

According to the CDC, 2020a; ECDC, (2020) the maintenance of social support networks during quarantine is also essential for mental health, since the rupture of social and physical connections is an important facilitator of negative psychological impacts.

Li et al., (2020b) state that people with suspected infection with the new coronavirus may develop obsessive-compulsive symptoms, such as repeated checking of body temperature. Asmundson\& Taylor, (2020) add that anxiety about health can also cause misinterpretation of bodily sensations, causing people to confuse them with signs of the disease and go unnecessarily to hospital services, as occurred in the H1N1 influenza pandemic, in 2009.

Furthermore, according to Brooks et al., (2020) measures such as isolation of suspicious cases, closure of schools and universities, social distance from the elderly and other at-risk groups, as well as quarantine, end up decreasing face-to-face connections. and routine social interactions, which can also be an important stressor during this period.

During the quarantine period, according to Goethals et al. (2020) one of the reasons for leaving home is physical activity. A study conducted by the Department of Internal Clinic, Faculty of Medicine of Botucatu, University Estadual Paulista (UNESP) suggests that the hormone irisin, released by muscles during physical activity, modulates genes associated with the result of severe coronavirus disease, and thus presents approaches promising for the treatment of COVID-19 infection as a therapeutic strategy to decrease regulatory genes for angiotensin-converting enzyme 2 - ACE2. 
However, the issue was also debatable as it could lead to a breach of isolation. This issue is important, as the impact of a sedentary lifestyle can do a lot of damage to the elderly population. Even though the elderly need to stay at home because they belong to the risk group for COVID-19 infection, it is necessary to avoid a sedentary lifestyle. In addition to physical activity being important for homeostasis, maintaining your level of independence and well-being is very important for mental health.

In addition to physical activity inducing the brain to release serotonin, dopamine, endorphins, "the hormones of happiness", and other neurotransmitters associated with well-being, they seem to stimulate the growth of nerve cells in the hippocampus, an area that regulates mood and which, in patients with depression, it is decreased in imaging exams. Early in the practice of physical activity, it induces autophagy, which is a cellular cleaning process, similar to Pac-Man, which devours damaged molecules, eliminating these components that kill cells and delay the onset of degenerative diseases. It is also possible that it also benefits telomeres directly, increases the number and quality of energy-producing mitochondria, which reduces the amount of oxidative stress, and increases the quality of sleep.

Insufficient physical activity during the waves of the Covid-19 pandemic, has deleterious effects on the psychosocial perspective and has been one of the main factors responsible for the increase in cases of several chronic diseases.

Currently, WHO recommends 300 minutes a week - or an hour of physical exercise for five days. Given this scenario, it is important to remain active during the Covid-19 crisis.

In the field of interpersonal relations, we can mention the new conditions that workers had to adapt, such as the home office. This condition in which the author Gaud Enzi (2021) makes a reflection in the form of questioning. She asks how to conduct a home office taking care of children and the home and also addresses that with the pandemic the tendency is for the discrepancy already experienced between individual possibilities and the speed of events and productive demands to increase. It also reports on the technical problems that these workers face and reflects on those who have lost their sources of income and those who work in the Unified Health System (SUS) and are daily exposed to the virus without PPE.

Gaud Enzi (2021) also reflects on the situation of women and says that they are the ones who suffer most from the inconvenience of continuous living with family members, as they are still the main responsible for the care economy, as they need to take care of the home, children, elderly and still continue to work for their companies. This, there is an important physical and emotional overload in these cases.

In addition, according to Lima et al., 2020; Ozili\&Arun, (2020) the fear of contracting the disease, COVID-19 has caused a feeling of insecurity in all aspects of life, from the collective to the individual perspective, from the daily functioning of society to changes in interpersonal relationships. Thus, Brooks et al. It concludes that as for mental health, it is important to say that the consequences of a 
pandemic are greater than the number of deaths. The health systems of countries collapse, health professionals are exhausted from long hours of work and, in addition, the most effective method of controlling the disease, which is social distance, has a considerable impact on the mental health of the population.

\subsection{THE COVID-19 CRISIS AND METAL HEALTH REPERCUSSIONS}

Understanding how a crisis presents itself in terms of the stages of evolution of the public health problem, according to WHO (2020B), is important to prepare health professionals and the population in general. This is because it is necessary to implement control strategies and alert the population to immediate and continued risks, since adherence to preventive measures will depend on how people perceive this threat. According to Brooks et al. (2020) it is recommended, therefore, to reduce the ambiguity of the information, especially that which can generate symptoms related to anxiety and stress. Therefore, evaluating a crisis as linked and progressive moments can collaborate to understand the specificities of stressors related to the problem situation and the care that must be provided.

\subsection{PRE-CRISIS}

WHO (2020a) describes that the first phase is the moment when the main information about the existence of the public health problem and the forms of contagion, transmission or development of the disease and its symptoms is passed on to the general population, in addition to consequences related to the illness factor. In the case of COVID-19, the first stage is associated with information about its initial impact, with recommendations for social distancing. In addition, information about the highest mortality in the elderly has been disseminated, despite the general low lethality of the disease, the characteristics partly similar to seasonal flu and transmission by direct or mediated contact with sick individuals.

In the pre-crisis phase, planning is essential. This moment should involve the risk assessment, which should be updated regularly, based on consultation with the technical guidance provided by WHO on COVID-19. Another recommended action involves the organization of financial resources and inputs, as well as the implementation of measures focused on controlling the transmission of the virus, such as social distance. WHO (2020b) adds that during a pandemic, it is important to increase the target population's awareness of the pathology, in order to decrease social anxiety and encourage behavioral changes that may help in controlling the disease. Therefore, communication is useful in the management of a health emergency that generates concern, anxiety and panic in society. 
As for mental health outcomes, Pancani et al. (2020) states that during the pre-crisis of COVID19 in Italy, the duration of quarantine and / or social distance as well as the inadequacy of the space used increased the occurrence of depressive symptoms. Limcaoco, Mateos, Fernandez, \&Roncero (2020) complement that acute stress is another factor present in this phase. In a survey of people from more than forty countries, such as Spain, Colombia and the Philippines, it was observed that 'greater concern in relation to contagion', 'female gender' and 'younger age groups' proved to be significant predictors for a higher level of stress . Lung, Lu, Chang, \& Shu, (2020) claim that depressive symptoms and increased behaviors related to substance dependence, such as smoking, also occurred in the long term, as pointed out in a study with Taiwanese healthcare professionals who cared for patients with suspected SARS).

\subsection{INTRACRISIS}

The intracrise period, or acute phase, according to Weissman et al. (2020) is the moment in which the health problem sets in, with the realization of the seriousness and vulnerability to illness, and the recognition of the eventual risk of contagion. In the crisis triggered by COVID-19, specifically in the intracrise, one can already see the high number and simultaneity of suspected and confirmed cases, a situation that tends to overburden the health system, leading to the collapse of assistance and aggravating the pandemic scenary. According to the Coronavirus Resource Center (2020), in situations of uncontrolled acceleration of contagion, hospitalizations and deaths by COVID-19 tend to be frequent, with high cumulative capacity and in a very short period, since the beginning of the presentation of symptoms or worsening from the board. This phenomenon causes intense repercussions on social functioning and has the potential to severely impact the mental health of society, such as the collapse of health and funeral systems that is taking place in April 2020 in Ecuador.

Park \& Park (2020) argue that with these groups, somatic symptoms, insomnia, anxiety, anger, rumination, decreased concentration, moodiness and loss of energy should receive special attention in mental health care. Brooks et al. (2020) add to this the heightening of concerns about yourself and others during the epidemic, which becomes an increasingly demanding routine during the intracrise. This tends to increase emotional, physical and social roles, facilitating the triggering, aggravation or relapse of mental disorders or physical illnesses.

\subsection{POST-CRISIS}

The third moment of the crisis can be understood as a phase of social reconstruction. After the decline in the number of new cases and the decrease in community transmission, measures of social distance are reduced and the outbreak of contamination tends to be under control, although 
it is not necessarily non-existent. People start to resume their usual activities, there is a gradual return to the functioning of institutions and commerce, in addition to a lower level of protection requirements against contagion. In the COVID-19 pandemic, until April 15, 2020, only China had started this phase, as cases of community transmission, hospitalizations and deaths began to decline.

\section{CONCLUSIONS}

With the outbreaks of COVID-19, there has been widespread panic and stress on mental health in global society. The general conclusion drawn by the ONU report is that unhappiness has increased worldwide as a result of the pandemic.

An important point in this discussion is the psychosocial vulnerability to which people are subject and the mental impact fostered by SarsCov 2, therefore, it is necessary that these issues are highlighted in this scenario, in order to seek psychosocial support strategies and networks.

Considering the context of social distance, the information disseminated by the media must be reliable, transparent, appropriate and verified, since it is essential for emotional control in times of crisis. In contrast, due to the ease of access to communication and information technologies, there is a great chance that the content that reaches individuals - depending on the communication vehicle - may have sensational, imprecise or faking impressions, which can generate a range harmful behavioral reactions to the population, such as fear, anger and aggression in this moment of crisis.

Furthermore, as a way to experience this situation in the most flexible and healthy way possible, it is important to try to establish a routine, have a moment of self-knowledge and reflection, take breaks from contact with situations or people that may cause anguish or discomfort, practice some work activity , of relaxation and leisure, and always try to strengthen the bonds - even at a distance - with individuals who can enable a greater collective well-being.

At moment, even after immunization, social detachment, avoiding fraternization and wearing masks demonstrate self-love and love for others, in addition to a preventive action against COVID-19.

A better tomorrow depends on our best today! 


\section{REFERENCES}

Asmundson, G. J. G., \& Taylor, S. (2020). Coronaphobia: fear and the 2019-nCoV outbreak. Journal of Anxiety Disorders, 70, 102196. http://dx.doi.org/10.1016/j.janxdis.2020.102196.

Barroso, B. I. de L., Souza, M. B. C. A. de, Bregalda, M. M., Lancman, S., \& Costa, V. B. B. da. (2020). A saúde do trabalhador em tempos de COVID-19: reflexões sobre saúde, segurança e terapia ocupacional. Cadernos Brasileiros de Terapia Ocupacional, 28(3), 1093-1102. https://doi.org/10.4322/25268910.ctoarf2091.

Brooks, S. K., Webster, R. K., Smith, L. E., Woodland, L., Wessely, S., Greenberg, N., \& Rubin, G. J. (2020). The psychological impact of quarantine and how to reduce it: rapid review of the evidence. The Lancet, 395(102227), 912-920. https:// doi.org/10.1016/S0140-6736(20)30460-8.

Centers for Disease Control and Prevention. (2020a). Social distancing, quarantine, and isolation: keep your distance to slow the spread. Atlanta: Author. Retrieved from http://www.cdc.gov/coronavirus/2019ncov/prevent-getting-sick/ social-distancing.html.

Chevance, A., Gourion, D., Hoertel, N., Llorca, P. M., Thomas, P., Bocher, R., Moro, M. R., Laprévote, V., Benyamina, A., Fossati, P., Masson, M., Leaune, E., Leboyer, M., \& Gaillard, R. (2020). Ensuring mental health care during the SARS-CoV-2 epidemic in France: A narrative review. L'Encephale, 46(3), 193-201. https://doi.org/10.1016/j.encep.2020.04.005.

Coronavirus Resource Center. (2020). Coronavirus COVID-19 global cases by the Center for Systems Science and Engineering (CSSE). Baltimore: Johns Hopkins University. Retrieved from http://coronavirus.jhu.edu/map.html.

Cucinotta, D., \& Vanelli, M. (2020). WHO declares COVID-19 a pandemic. Acta Biomedica, 91(1), 157160. https://doi.org/10.23750/abm.v91i1.9397.

European Centre for Disease Prevention and Control. (2020). Considerations relating to social distancing measures in response to COVID-19: second update. Stockholm: Author. Retrieved from http://www.ecdc.europa.eu/sites/default/ files/documents/covid-19-social-distancing-measuresg-guidesecond-update.pdf.

Faro, A. et. al. COVID-19 e saúde mental: a emergência do cuidado. Disponível em: https://www.scielo.br/scielo.php?script=sci_arttext\&pid=S0103-166X2020000100507. Acesso em: 20 mar 2021.

Gaudenzi, P. (2021). Cenários brasileiros da Saúde Mental em tempos de Covid-19: uma reflexão. https://doi.org/https://doi.org/10.1590/SciELOPreprints.1739.

Goethals, L., Barth, N., Guyot, J., Hupin, D., Celarier, T., \& Bongue, B. (2020). Impact of home quarantine on physical activity among older adults living at home during the COVID-19 pandemic: Qualitative interview study. Journal of Medical Internet Research, 22(5), 1-5. https://doi.org/10.2196/19007.

Honorato, E. J. S., Neves, A. L. M. das, Therense, M., Martins, G. de C., Marangoni, V. S. L., Silva, T. A. da, Souza, D. C. de, Costa, L. V. da, \& Lemos, S. M. (2020). Waves of mental health Demands during 
the COVID-19 pandemic. Research, Society and Development, 9(8). https://doi.org/10.33448/rsdv9i8.6204.

Kola, L., Kohrt, B. A., Hanlon, C., Naslund, J. A., Sikander, S., Balaji, M., Benjet, C., Cheung, E. Y. L., Eaton, J., Gonsalves, P., Hailemariam, M., Luitel, N. P., Machado, D. B., Misganaw, E., Omigbodun, O., Roberts, T., Salisbury, T. T., Shidhaye, R., Sunkel, C., ... Patel, V. (2021). COVID-19 mental health impact and responses in low-income and middle-income countries: reimagining global mental health. The Lancet. Psychiatry, 0366(21), 1-16. https://doi.org/10.1016/S2215-0366(21)00025-0.

Li, W., Yang, Y., Liu, Z. H., Zhao, Y. J., Zhang, Q., Zhang, L., ... Xiang, Y. T. (2020b). Progression of mental health services during the COVID-19 outbreak in China. International Journal of Biological Sciences, 16(10), 1732-1738. http://dx.doi. org/10.7150/ijbs.45120.

Lima, C. K. T., Carvalho, P. M. M., Lima, I. A. S., Nunes, J. A. V. O., Saraiva, J. S., Souza, R. I., ... Rolim Neto, M. L. (2020). The emotional impact of coronavirus 2019-Ncov (new Coronavirus Disease). Psychiatry Research, 287, e112915. https://doi.org/10.1016/j.psychres.2020.112915.

Limcaoco, R. S. G., Mateos, E. M., Fernandez, J. M., \& Roncero, C. (2020). Anxiety, worry and perceived stress in the world due to the COVID-19 pandemic: preliminary results. MedRxivPreprint. https://doi.org/10.1101/2020.04.03.20043992.

Lung, F. W., Lu, Y. C., Chang, Y. Y., \& Shu, B. C. (2009). Mental symptoms in different health professionals during the SARS attack: a follow-up study. Psychiatric Quarterly, 80(2), 107-116. https://doi.org/10.1007/s11126-009-9095-5

McConnell, D. (2020). Balancing the duty to treat with the duty to family in the context of the COVID19 pandemic. Journal of Medical Ethics, 46(6), 360-363. https://doi.org/10.1136/medethics-2020106250.

Miriane de Oliveira, Maria Teresa De Sibio, Lucas Solla Mathias, Bruna Moretto Rodrigues, Marna Eliana Sakalem, Célia Regina Nogueira. Irisin modulates genes associated with severe coronavirus disease (COVID-19) outcome in human subcutaneous adipocytes cell culture, Molecular and Cellular Endocrinology, Volume 515, 2020, 10917, ISSN 0303-7207, https://doi.org/10.1016/j.mce.2020.110917. (https://www.sciencedirect.com/science/article/pii/S0303720720302173)

Ornell, F., Halpern, S. C., Paim Kessler, F. H., \& de Magalhães Narvaez, J. C. (2020). The impact of the COVID-19 pandemic on the mental health of healthcare professionals. Cadernos de Saude Publica, 36(4). https://doi.org/10.1590/0102-311X00063520.

Ornell, F., Schuch, J. B., Sordi, A. O., \& Kessler, F. H. P. (2020). "'Pandemic fear"” and COVID-19: Mental health burden and strategies. Brazilian Journal of Psychiatry, 42(3), 232-235. https://doi.org/10.1590/1516-4446-2020-0008.

Ozili, P., \& Arun, T. (2020). Spillover of COVID-19: impact on the global economy. SSRN Preprints. https://doi.org/10.2139/ ssrn.3562570.

Pancani, L., Marinucci, M., Aureli, N., \& Riva, P. (2020). Forced social isolation and mental health: a study on 1006 Italians under COVID-19 quarantine. PsyArXiv Preprints. https://doi.org/10.31234/osf.io/uacfj. 
Teixeira, C. F. de S., Soares, C. M., Souza, E. A., Lisboa, E. S., Pinto, I. C. de M., de Andrade, L. R., \& Espiridião, M. A. (2020). The health of healthcare professionals coping with the covid-19 pandemic. Ciencia e Saude Coletiva, 25(9), 3465-3474. https://doi.org/10.1590/1413-81232020259.19562020.

Varga, T. V., Bu, F., Dissing, A. S., Elsenburg, L. K., Bustamante, J. J. H., Matta, J., van Zon, S. K. R., Brouwer, S., Bültmann, U., Fancourt, D., Hoeyer, K., Goldberg, M., Melchior, M., Strandberg-Larsen, K., Zins, M., Clotworthy, A., \& Rod, N. H. (2021). Loneliness, worries, anxiety, and precautionary behaviours in response to the COVID-19 pandemic: a longitudinal analysis of 200,000 Western and Northern Europeans. The Lancet Regional Health - Europe, 000, 100020. https://doi.org/10.1016/j.lanepe.2020.100020.

Weissman, G. E., Crane-Droesch, A., Chivers, C., ThaiBinh, L., Hanish, A., Levy, M. Z., ... Halpern, S. D. (2020). Locally informed simulation to predict hospital capacity needs during the COVID-19 pandemic [Ahead of print]. Annals of Internal Medicine. https://doi.org/10.7326/M20-1260.

World Health Organization. (2020). Dia Mundial da Saúde Mental: uma oportunidade para dar o pontapé inicial em uma grande escala de investimentos. OPAS/OMS Brasil. https://www.paho.org/bra/index.php?option=com_content\&view=article\&id=6263:dia-mundial-dasaude-mental-uma-oportunidade-para-dar-o-pontape-inicial-em-uma-grande-escala-deinvestimentos \&Itemid=839.

World Health Organization. (2020a). Coronavirus disease 2019 (COVID-19): situation report - 78. Geneva: Author. Retrieved from http://www.who.int/docs/default-source/coronaviruse/situationreports/20200407-sitrep-78-covid-19.pdf?sfvrsn=bc43e1b_2.

World Health Organization. (2020b). Report of the WHO-China joint mission on coronavirus disease 2019 (COVID-19). Geneva: Author. Retrieve.

Xiang, Y.-T., Yang, Y., Li, W., Zhang, L., Zhang, Q., Cheung, T., \& Ng, C. H. (2020). Timely mental health care for the 2019 novel coronavirus outbreak is urgently needed. The Lancet Psychiatry, 7(3), 228229. https://doi.org/10.1016/S2215-0366(20)30046-8.

Yao, H., Chen, J. H., \& Xu, Y. F. (2020). Patients with mental health disorders in the COVID-19 epidemic. The Lancet Psychiatry, 7(4), e21. https://doi.org/10.1016/S2215-0366(20)30090-0.

Zhu, Y., Chen, L., Ji, H., Xi, M., Fang, Y., \& Li, Y. (2020). The Risk and Prevention of Novel Coronavirus Pneumonia Infections Among Inpatients in Psychiatric Hospitals. Neuroscience Bulletin, 36(3), 299-302. https://doi.org/10.1007/s12264-020-00476-9. 